\title{
O PROFESSOR-ARTISTA NA FORMAÇÃO UNIVERSITÁRIA EM TEATRO
}

\author{
THE PROFESSOR-ARTIST IN THE \\ UNDERGRADUATE THEATRE STUDIES \\ Diogo Horta ${ }^{1}$, Mariana de Lima e Muniz ${ }^{2}$
}

\section{RESUMO}

Este texto reflete sobre o docente na graduação em Teatro, a partir da pesquisa comparativa realizada na EBA/UFMG e na UFSJ de 2012 a 2014. As reflexões oriundas da observação e da prática docente em disciplinas de improvisação nestas instituições permitem identificar a importância da atuação do professor como artista na sala de aula, fortalecendo a experiência do aluno na pesquisa e na prática do teatro.

Palavras-chave: Ensino. Teatro. Professor-artista.

${ }^{1}$ Mestre em Artes pela Escola de Belas Artes/ UFMG

${ }^{2}$ Professora titular da EBA/UFMG e coordenadora do Programa de PósGraduação em Artes da EBA/UFMG

\section{INTRODUÇÃO}

Desenvolvemos, no programa de Pós-Graduação em Artes da Escola de Belas Artes da UFMG - EBA/UFMG, uma pesquisa de mestrado sobre a formação universitária em Teatro, a partir do ensino da improvisação teatral na EBA/UFMG e na Universidade Federal de São João del-Rei - UFSJ, tendo como base o denominado Sistema Impro, do professor e diretor inglês Keith Johnstone (HORTA, 2014). 
Além de analisar os conteúdos abordados nas disciplinas e as percepções dos alunos a partir da experiência com a improvisação, foram observados aspectos relevantes com relação à prática docente em Teatro, que podem também contribuir para a reflexão sobre essa prática em outros contextos universitários.

Dessa forma, este artigo tem como objetivo compartilhar a pesquisa realizada, aprofundando-se em aspectos importantes para a compreensão da docência em Teatro. Para isso, apresentaremos um panorama geral da pesquisa e, posteriormente, nos dedicaremos a refletir sobre a prática docente a partir de tal experiência.

\section{ABORDAGEM E INVESTIGAÇÃO}

O teatro é uma das linguagens artísticas mais antigas da cultura ocidental e se confunde com o próprio desenvolvimento do homem no que diz respeito à imitação, ao jogo dramático infantil e à comunicação em si (COURTNEY, 2003). Desde os primórdios do teatro ocidental na Grécia até os dias atuais, o teatro apresentou características muito diferentes, modificando suas concepções e práticas. Do mesmo modo, evoluíram também os processos formativos e criativos em teatro, possibilitando a sua inserção, a partir do século XX, na grade dos cursos de ensino superior no mundo (HORTA, 2014).

No Brasil, data dos anos 1950 a criação da primeira graduação em Interpretação Teatral, na Universidade Federal do Rio Grande do Sul - UFRGS (GUSMÃO; MUNIZ, 2012). A Universidade de São Paulo - USP e a Universidade Federal do 
Estado do Rio de Janeiro - Unirio foram as próximas a criar cursos de graduação na área teatral, na década de 1970. A partir dessas iniciativas, outros cursos de graduação foram criados, incluindo as modalidades bacharelado e licenciatura em todo o Brasil.

Na UFMG, o curso de graduação em Teatro foi criado em 1998, dentro da Escola de Belas Artes. Inicialmente se chamou Artes Cênicas, nome alterado depois para se adequar às novas diretrizes legais, após o processo de avaliação do Instituto Nacional de Estudos e Pesquisas Educacionais Anísio Teixeira - INEP, em 2003 (GUSMÃO; MUNIZ, 2012). No curso, existem as modalidades licenciatura e bacharelado, sendo que este possui a habilitação em Interpretação Teatral. Na UFSJ, o curso de graduação em Teatro foi criado em 2009, como parte do Programa de Apoio a Planos de Reestruturação e Expansão das Universidades Federais - REUNI, e também possui as modalidades licenciatura e bacharelado.

Nossa pesquisa teve como objetivo observar como se deu o trabalho com o sistema de prática improvisacional criado pelo professor, diretor e dramaturgo inglês Keith Johnstone - e denominado por Theresa Dudeck (2013) como Sistema Impro - na formação universitária em Teatro da UFMG e da UFSJ.

O Sistema Impro é uma abordagem para o treinamento do ator que tem como foco encorajar a espontaneidade, a criação colaborativa, a cooperação e a prática cênica através de jogos, exercícios e cenas improvisadas. É considerado um sistema porque sua melhor funcionalidade depende de que todos os componentes estejam trabalhando harmoniosamente. 
Esse sistema foi a principal referência das disciplinas de Improvisação Teatral ministradas, no período da coleta de dados, pela professora Mariana de Lima e Muniz na UFMG e pelo professor Diogo Horta na UFSJ, também autores deste artigo. Esse sistema de trabalho foi escolhido pelo fato de ser uma prática já bastante utilizada por nós, como atores e diretores, em espetáculos teatrais improvisados, um estilo teatral no qual a improvisação não é um processo, e sim o resultado em si, sendo denominado improvisação como espetáculo (MUNIZ, 2005). Dessa forma, o nosso trabalho artístico foi a base para a prática pedagógica e para a investigação desenvolvida, sendo parte dela compartilhada neste texto.

As conclusões da pesquisa permitiram a percepção de alguns fatores relacionados à prática da improvisação, tanto para os alunos como para os professores, que contribuem para reflexões a respeito de atitudes pedagógicas no ensino do teatro. No Sistema Impro, a forma como o professor conduz as atividades é um dos elementos principais das propostas de Johnstone. Segundo o diretor e dramaturgo inglês, um professor pode obter resultados usando quaisquer métodos, bem como pode arruinar qualquer um, dependendo da maneira como conduz as atividades (JOHNSTONE, 1992).

Johnstone se dedicou amplamente ao estudo da forma como as crianças se relacionavam com a criação, assim como às suas relações com os professores e com os processos criativos em sala de aula. Quando publicou seu primeiro livro, chamado Impro - Improvisation and Theatre, cuja primeira edição é de 1979, o autor inglês estava convencido de que o processo educacional inglês daquela época destruía e podava a criatividade dos 
alunos. A partir de então, desenvolveu o próprio sistema de trabalho, com o objetivo inicial de promover, potencializar e instigar o processo criativo de adultos e crianças.

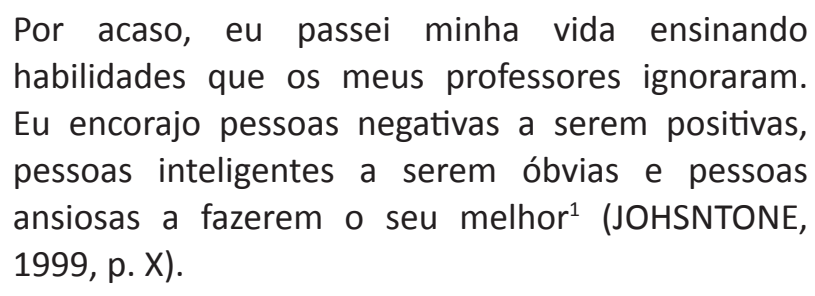
habilidades que os meus professores ignoraram. Eu encorajo pessoas negativas a serem positivas, pessoas inteligentes a serem óbvias e pessoas ansiosas a fazerem o seu melhor ${ }^{1}$ (JOHSNTONE, 1999, p. X).

Nesse sentido, o professor que trabalha a partir do Sistema Impro deve adotar uma postura que busque alterar a percepção do erro por parte do estudante (DUDECK, 2013). Essa alteração deve permitir, por exemplo, que o estudante aceite o erro como algo positivo e se divirta a partir dele. A pesquisadora norte-americana Patrícia Ryan Madson (2005) afirma que os erros não devem ser considerados como algo a ser evitado, uma que vez que são necessários e fazem parte de nosso sistema operacional em qualquer processo criativo ou de aprendizagem.

Em nossa pesquisa, observamos que o erro geralmente se apresentava quando o grupo desejava muito acertar em um determinado jogo de regras ou em cenas improvisadas. A partir do momento em que aceitava o risco e a possibilidade do fracasso como algo inerente a qualquer jogo ou cena improvisada, as expectativas do grupo diminuíam, e os alunos se sentiam mais relaxados e livres para criar.

1 "By happenstance I've spent my life teaching the skills that my teachers had ignored. I encourage negative people to be positive, and clever people to be obvious, and anxious people to do their best" (Tradução nossa). 
Um conceito importante do Sistema Impro é denominado Status e diz respeito às relações que os atores estabelecem em uma cena improvisada. São relações correspondentes à dominação e à submissão que se dão em diversos níveis entre os personagens e destes com objetos e espaços. Como na vida, essas relações são fluidas e se alteram a todo o momento, de forma mais ou menos consciente. Sempre estamos subindo ou abaixando nossos status, dominando ou sendo dominados, em uma dinâmica próxima à de uma gangorra.

É importante ressaltar que o conceito de Status aqui apresentado não se refere ao status social, ou seja, à posição que um sujeito ocupa na sociedade, e sim à relação de um personagem com outro, independentemente de sua posição social.

Eu deveria realmente falar sobre dominação e submissão, mas eu criaria resistência. Estudantes que aceitariam prontamente subir ou abaixar seus status poderiam se opor se fosse pedido para 'dominar' ou 'submeter'. Status me parece ser um termo útil, desde que entendida a diferença entre o status que você é e o status que você desempenha ${ }^{2}$ (JOHNSTONE, 1992, p. 36).

Dessa forma, a utilização do termo Status, no lugar de dominação e submissão, permitiria uma abertura nas formas de relação e no tipo de comportamento em cena. Além disso,

\footnotetext{
2 "I should really talk about dominance and submission, but l'd create a resistance. Students who will agree readily to raising or lowering their status may object if asked to 'dominate' or 'submit'. Status seems to me to be useful term, providing the difference between the status you are and the status you play is understood" (Tradução nossa).
} 
o princípio da gangorra - quando um personagem eleva e o outro abaixa o próprio status - é muito importante para desviar os atores da preocupação com a história, ou com o próximo passo da improvisação, e para conectá-los sempre ao momento presente das relações em cena.

Johnstone também trabalha com o princípio da gangorra de status como professor, na relação com seus alunos, de forma quase imperceptível e sempre muito bem-humorada. $O$ autor observa que, ao provocar uma alteração na relação de Status com seus alunos (sobretudo ao abaixar o status do professor e subir o do aluno), o processo de ensino-aprendizagem se torna mais fluido, uma vez que os alunos se sentem mais livres para criar, atuar e aprender.

Isso também possibilita que o professor esteja sempre em jogo com os alunos, em uma relação metalinguística com o Sistema Impro. Assim, nas aulas de improvisação, utilizamos, como professores, vários procedimentos do sistema para trabalhar com os alunos. Com o tempo, à medida que vão se familiarizando com esses procedimentos técnicos, os alunos começam a perceber esse jogo metalinguístico e a se aproximar dos professores.

Por esses motivos, segundo Dudeck (2013), as ideias de Johnstone em seu primeiro livro representam o início de uma contínua luta, ao que Paulo Freire (2011) chamou de "Educação Bancária": "Eu vejo o Keith como um educador freiriano que defende fortemente a desconstrução da relação entre o 'professor totalitário' versus o 'estudante passivo' e cria uma 
parceria no lugar disso" (DUDECK, 2013, p. 7) ${ }^{3}$. Ainda segundo a autora norte-americana, a crença de Johnston de que o processo de aprendizagem não é estático para professores e alunos e de que todos estão em processo de transformação é crucial para seu sistema.

Durante um semestre da disciplina intitulada "Prática de Atuação: Teorias e Métodos de Atuação Cênica: Impro" na UFSJ e dois semestres da disciplina intitulada "Oficina de Improvisação II" na UFMG, pudemos observar, analisar e colocar em prática esses e outros princípios e práticas do Sistema Impro, a fim de refletir sobre a formação universitária em Teatro, no que diz respeito à improvisação.

A disciplina na UFSJ teve 27 alunos frequentes e que participaram ativamente das aulas e do processo de investigação proposto nesse contexto, em que o professor Diogo Horta ministrou todas as aulas da disciplina de 72 horas. Por esse motivo, os alunos foram convidados a escrever relatórios ao final de cada aula, sendo instigados a apontar comentários sobre os conceitos e práticas do Impro a partir da experiência diária na disciplina, bem como a responder uma questão sobre o processo das aulas e a formação obtida no final da disciplina. Além disso, o professor e pesquisador também escreveu relatórios, ao final de cada aula, em um caderno de campo que se propunha a detalhar as percepções de cada jogo ou exercício e que foi confrontado com os relatórios dos

3 "I see Keith as a Freirian educator who strongly advocates dismantling the 'totalitarian teacher' versus 'passive student' relationship and creating a partnership in its place" (Tradução nossa). 
alunos na fase de análise, permitindo uma compreensão da experiência nesse contexto.

A disciplina na UFMG teve, no primeiro semestre de pesquisa, 17 alunos e, no semestre subsequente, 22 alunos, tendo sido ministrada pela professora Mariana de Lima e Muniz, com contribuição do professor Diogo Horta na condução de alguns exercícios, sendo que esse ficou mais dedicado à observação da prática e à escrita de relatórios de cada aula no caderno de campo. Ao final das aulas, os alunos comentaram, oralmente, sobre a experiência, e as observações foram anotadas pelo pesquisador. No final do processo da disciplina, que tinha carga horária de 90 horas, os alunos também foram convidados a escrever suas percepções sobre o curso a partir de um questionário.

Dessa forma, com processos de coleta similares, mas com especificidades de acordo com o contexto vivenciado, os pesquisadores confrontaram, primeiramente, as anotações dos alunos e dos cadernos de campo de cada instituição e, posteriormente, cruzaram os dados coletados nas duas universidades, percebendo pontos similares e diferentes da vivência com a improvisação teatral.

A partir do levantamento desses pontos de cruzamento, buscamos dialogar com as referências especializadas sobre o tema, gerando apontamentos sobre o processo de ensinoaprendizagem em Teatro, tanto pela ótica do professor quanto pela do aluno. Dessa maneira, abordaremos a seguir como a nossa prática docente foi influenciada pelas ideias de Johnstone e como puderam consolidar um ambiente de troca, aprendizagem e experiência a partir da improvisação 
teatral, contribuindo para a formação discente em nossas universidades.

\section{A DOCÊNCIA EM TEATRO: ALUNOS E PROFESSORES EM COOPERAÇÃO}

Nas disciplinas ministradas e observadas em nosso estudo de caso, foi possível ver uma alteração na relação entre professores e alunos, no sentido de aproximá-los e instaurar entre eles um diálogo efetivo e afetivo. Em primeiro lugar, porque os professores utilizaram estratégias para equalizar seus Status com os dos alunos. E, em segundo, por abordarem conteúdos que impedem a criação da dicotomia professoraluno, uma vez que esses conteúdos devem ser compartilhados e experienciados, como a aceitação de ideias, a confiança no primeiro impulso, a cooperação em cena, a ampliação da escuta, entre outros.

Johnstone (1992) apresenta que uma das primeiras coisas que ele faz ao encontrar um grupo de alunos é sentar-se no chão, fazendo com que o seu Status abaixe imediatamente, eliminando, ao menos em parte, possível medo ou resistência com relação ao professor por parte dos alunos. Em nossa experiência pedagógica, nos colocamos sempre no mesmo nível dos alunos em termos espaciais, independentemente se sentávamos no chão ou em cadeiras. Professores e alunos se colocavam assim, uns aos lados dos outros, voltados para a área cênica, nos momentos de improvisação, ou em roda, nos momentos de diálogo e de explicação de conteúdos. 
Dessa forma, a relação espacial não permitia uma visão privilegiada ou um lugar privilegiado ao professor, tendo todos um lugar equivalente na sala de aula. Outra estratégia utilizada com o intuito de aproximar os Status se deu com a realização de jogos e exercícios de aquecimento pelos professores com o grupo de alunos. O professor dava a instrução do jogo e depois se colocava como mais um jogador, misturando-se aos alunos e eliminando a presença de qualquer tipo de olhar externo ou de autoridade no jogo, o que fazia com que ocorresse uma experiência de aprendizado sem julgamento e sem atuantes e observadores, todos, sem exceção, eram jogadores do mesmo jogo.

Esse processo permite que a experiência do aluno seja fator crucial para o aprendizado (GALVÁN, 2013), para além dos comentários e orientações feitos pelo professor no decorrer da aula. Dessa forma, a partir do momento em que compartilham uma experiência, professores e alunos estabelecem muitos momentos em que não há distinção entre um e outro. 0 professor provoca e os alunos reagem, da mesma forma como os alunos provocam e o professor reage.

Nesse sentido, é perceptível o tanto que os professores se envolvem e se afetam pelas cenas e pelos exercícios realizados e como isso parece envolver os alunos e facilitar as instruções enquanto as cenas acontecem, e também nos comentários posteriores. Cabe ressaltar, mais uma vez, que aspectos fundamentais para o trabalho de uma cena improvisada foram primordiais para a ação e a condução do professor na sala de aula. 
Pode-se citar, por exemplo, a disposição constante para a aceitação e a cooperação dos professores para as propostas dos alunos, disposição fundamental para a prática da improvisação, a qual nós, os professores, estamos sempre atentos, por sermos também atores-improvisadores. Isso nos possibilitou, inclusive, improvisar junto aos alunos em alguns momentos, levando-os a se sentirem estimulados ao nos verem improvisar e correr riscos, como comentaram em alguns relatórios. Dessa forma, isso nos aproximava deles, e eles se percebiam mais à vontade para estar em cena.

O fato de os professores realizarem os jogos e exercícios de aquecimento com os alunos é relevante, nesse sentido, porque os professores se aqueciam para estarem disponíveis para a improvisação e para a escuta ampliada dos alunos, além de fazer com que houvesse uma potencialização no jogo coletivo, contribuindo para o processo de ensino-aprendizagem.

Em jogos de regra, é importante que o professor também cometa erros, pois isso contribui para diminuir a ansiedade da turma e propiciar uma relação positiva com nossas falhas e com as dos outros, além de ser mais uma estratégia para abaixar o Status do professor. É por essas razões, dentre outras observadas, que concluímos em nossa experiência que o fato de o professor ser também artista influi positivamente nas aulas ministradas.

A pesquisadora mexicana Patrícia Cardona nos inspira a descobrir a força do professor que se mantém criador e artista nas aulas de arte, dizendo que o professor "é um artista ou 
deve ser um artista que parte de sua poética para formar outros artistas" (CARDONA, 2012, p. 16)

\begin{abstract}
A poética do ensino se desdobra na presença integradora, provocadora, estimulante e apaixonada do professor/criador frente ao que aprende, entendendo que ambos, em todo momento, ensinam e aprendem. Essa presença magnética se pode reconhecer no uso do corpo, da voz; na maneira de apresentar os estímulos; na pirotecnia do ritmo "cênico" para dirigir uma sala de aula; na construção de um imaginário para expor os temas por meio do jogo ou do mistério ou do desafio que supõem os mesmos ${ }^{5}$ (CARDONA, 2012, p. 81).
\end{abstract}

Nesse sentido, em nossa pesquisa de condução e observação das aulas de improvisação na UFMG e na UFSJ, o processo de ensino-aprendizagem foi beneficiado pela experiência artística prévia do professor e pela partilha dessa experiência na sala de aula.

Outro ponto observado na dinâmica entre professores e alunos são os comentários feitos após cada cena improvisada. Esses comentários têm como função refletir sobre a prática realizada em cena e influem positivamente no aprendizado

\footnotetext{
4 "Es un artista o debe ser un artista que parte de su poética para formar otros artistas" (Tradução nossa).

5 "La poética de la enseñanza se despliega en la presencia integradora, provocadora, estimulante y apasionada del maestro/creador frente al que aprende, en el entendido de que ambos, en todo momento, enseñan y aprenden. Esa presencia magnética puede reconocerse en el uso del cuerpo, de la voz; en la manera de presentar los estímulos; en la pirotecnia del ritmo 'escénico' para dirigir una clase; en la construcción de un imaginário para exponer los temas mediante el juego o el mistério o el reto que suponen los mismos" (Tradução nossa).
} 
do aluno, pois é um retorno do desempenho técnico e criativo na improvisação. As duas experiências pedagógicas aqui analisadas demonstraram que é fundamental dialogar com os alunos que estão na plateia ou que fizeram a cena, em cada exercício vivenciado. Dessa forma, a prática da observação também se constitui em elaboração e aprendizado para todos os envolvidos no processo.

Com relação à sequência de conteúdos, apesar de termos elaborado um plano de aula que nos serviu como guia durante o semestre, estivemos muito atentos às necessidades e às habilidades de cada grupo, a cada etapa, fazendo modificações e adaptações sempre que era preciso. Nesse sentido, existe um plano de aula, mas não um roteiro fechado de cada aula, já previsto do início ao fim do semestre.

Após cada aula, sentávamos e discutíamos quais seriam os jogos e exercícios mais adequados para esclarecer melhor um procedimento ou resolver um determinado problema identificado. Isso também poderia ocorrer durante a aula. Estivemos sempre abertos a abandonar nossos roteiros, caso os alunos demonstrassem vontade de se alongar em determinada proposta ou se daí surgissem novas possibilidades.

Se o grupo sugeria algum jogo, o incluíamos em nosso plano e nos mantínhamos disponíveis para inventar ou adaptar novos jogos e exercícios. Em outras palavras, improvisávamos a aula como se improvisa uma cena: a partir de premissas muito objetivas, nos adaptávamos e avaliávamos o que acontecia momento a momento. 
O tempo disponível para os alunos praticarem em sala de aula foi fundamental, bem como a possibilidade de que todos fizessem os jogos propostos, sendo que isso foi algo que levamos em consideração na elaboração dos planos de aula. Por isso, é preciso colocar em diálogo espaço físico, número de alunos, objetivos, comportamentos em aulas anteriores, motivações, emoções, enfim, toda a percepção do professor com relação ao processo conduzido por ele.

Uma solução que encontramos para que todos sempre fizessem todos os exercícios foi misturar momentos de pequenos grupos fazendo o jogo diante dos demais com momentos em que todos faziam ao mesmo tempo. Apesar da dispersão que esses momentos coletivos geravam, era possível ir a cada grupo e observar por instantes o que estava sendo feito, dando, imediatamente, um retorno que contribuísse para o desenvolvimento da cena.

Esses foram momentos importantes para trabalhar com os alunos uma percepção diferenciada da noção de erro, fazendo com que eles valorizassem mais a experiência em si que as relativas percepções de sucesso e fracasso. No entanto, avaliamos que esse é um ponto que merece mais atenção, para que os alunos possam, de fato, buscar alterar a relação que mantêm com o erro, tão presente nos processos educacionais em geral, tratando-o como algo essencialmente negativo.

Por isso, ao invés de incitarem nos alunos o medo de errar e de punirem aqueles que erram (algo que pode ser, inclusive, relativo, conforme as disciplinas), os professores deveriam trabalhar a noção de que o erro será essencial para o aprendizado, para a reflexão e para a compreensão mais ampla 
de todo e qualquer conteúdo, deixando os alunos mais livres e relaxados na sala de aula.

Também é importante observar que os alunos nem sempre reagem ou respondem da mesma maneira aos mesmos exercícios. "Há conhecimentos ou exercícios que podem não ter nenhuma relação aparente com aquilo que se pretende e que têm um efeito secundário, indireto." (LASSALLE; RIVIÈRE, 2010, p. 36). Dessa forma, foi fundamental a percepção do todo do processo, sendo importante reconhecer que, apesar de alguns objetivos estarem mais claros em um determinado exercício, outros aspectos também estarão sendo trabalhados.

A cooperação e a benevolência são os dois eixos centrais da proposta de Johnstone e devem ser fundadas não apenas durante os exercícios, mas do início ao fim das aulas, durante todos os momentos de instrução do professor e dos comentários sobre a prática. 0 professor e o grupo de alunos devem aprender, em primeiro lugar, a cooperarem uns com os outros para que a experiência se concretize, a percepção seja ativada e o aprendizado seja consolidado.

Essa seria, portanto, uma experiência educativa. Experiência, porque existe uma forma de interação entre dois elementos - agente e situação - que se influenciam mutuamente. E educativa, porque aqueles que integram o processo da experiência utilizam o pensamento e a inteligência a fim de perceber fatores até então não percebidos e que proporcionarão, assim, a aquisição de novos conhecimentos (TEIXEIRA; WESTBROOK, 2010). 
Alguns elementos que contribuíram para a experiência educativa, encorajada pela cooperação e pela benevolência na sala de aula, foram as emoções positivas e a diversão, observadas com ênfase na UFSJ e na EBA/UFMG. Um aspecto que nos pareceu fundamental com relação a uma prática pedagógica divertida é o alto índice de motivação e o envolvimento que ela provoca nos alunos. Isso pôde ser observado tanto durante as disciplinas do estudo de caso, quanto na posterior análise dos relatos e das respostas aos questionários aplicados aos alunos.

Esse é um fator que consideramos essencial para uma prática pedagógica, sobretudo quando se trata de disciplinas relacionadas ao fazer artístico e à criação individual ou coletiva. Isso porque é preciso envolver os alunos inteiramente na atividade para que eles possam responder às propostas e provocações do professor com consistência e compromisso.

Um dos aspectos que observamos com relação à diversão é que ela está diretamente relacionada com o humor e com as emoções positivas, o que poderia favorecer, como apresenta Lubart (2012), os processos criativos que são essenciais para a prática artística. Dessa forma, o desencadeamento de emoções positivas (VANDENBERGHE; SILVESTRE, 2013), em nosso caso, produzidas por atividades divertidas na maioria das vezes, poderia favorecer e/ou potencializar estados criativos.

Segundo Lubart (2012), a síntese das pesquisas que associam emoção e criatividade sugere que os estados emocionais positivos favorecem a fluidez ideacional e, portanto, o potencial criativo. Dessa forma, "quanto mais o participante está com um estado emocional geral positivo, mais ele é fluido 
e flexível" (LUBART, 2011, p. 57) ${ }^{6}$. Ainda no campo das emoções positivas, Cardona (2012, p. 118) afirma que o humor "evita o patético e é o antídoto contra a solenidade que dramatiza desnecessariamente a educação"7.

Dessa forma, conclui-se que as práticas de jogos e exercícios do Sistema Impro, bem como as improvisações em si, provocaram e encorajaram a experiência discente na UFSJ e na EBA/UFMG, contribuindo para seus processos de ensino-aprendizagem. Ressaltamos esse aspecto a fim de aguçar a percepção do divertimento e das emoções positivas em práticas pedagógicas, com o intuito de incentivar a vivência consciente desses elementos, sobretudo nas aulas de Teatro.

Destaque-se, porém, que esses são alguns elementos que podem contribuir para as aulas na graduação em Teatro e que puderam ser observados e aplicados em disciplinas de improvisação teatral. Para além deles, é notória a atuação do docente na condição de artista, fazendo das próprias aulas um fazer artístico que possa inspirar, conduzir e incentivar os alunos em uma experiência educativa legítima.

Como apresenta Cardona (2012), é preciso que todos os canais de percepção e fontes de inspiração estejam abertos no processo de ensino-aprendizagem em Artes, estando o professor consciente de que há conteúdos que não são ensinados, são provocados.

\footnotetext{
6 "Plus le participant est dans un état émotionnel général positif, plus il est fluide et flexible" (Tradução nossa).

7 "Evita lo patético y es el antídoto contra la solemnidad que dramatiza innecesariamente la educación” (Tradução nossa).
} 


\section{CONSIDERAÇÕES FINAIS}

A observação e a prática nos processos das disciplinas na UFSJ e na EBA/UFMG permitem constatar que a experiência educativa é única e se constitui no presente das aulas, por mais que essas estejam sustentadas sobre um sistema de ensino, como o Sistema Impro, por exemplo. Dessa forma, a presença do professor e de suas experiências como artista se mostra determinante para a concepção das propostas feitas na sala de aula.

O trabalho com as técnicas e práticas deve ser entendido como um caminho para a expressão artística, e não como um fim em si mesmo. Em arte, o professor deve conduzir os alunos para que eles possam encontrar em si mesmos um caminho para a criatividade, provocando a descoberta de elementos-chave para todo e qualquer processo de criação.

Ao buscar uma prática pedagógica divertida (no sentido de inspirar emoções positivas) a partir das atitudes e das atividades na sala de aula e ao tentar alterar o medo do erro e, inclusive, o que poderia ser considerado como erro, o professor promove uma mudança na relação com os alunos. Isso não significa perder o controle da turma ou diminuir as exigências feitas aos alunos, significa instaurar uma atmosfera na qual seja possível identificar que o foco principal é o aprendizado, a formação crítica e a produção de conhecimentos. E que, a partir dessa atmosfera, os alunos tenham capacidade e tempo para refletirem sobre a área estudada e para se colocarem individualmente em relação com o conteúdo abordado, 
percebendo suas relações com o mundo e com os demais temas estudados em outras disciplinas.

Nesse sentido, é relevante que docentes e discentes estabeleçam uma relação diferenciada na sala de aula, fundada na cooperação e na parceria. A partir daí, alunos e professores podem se reconhecer inacabados, fazendo do processo educativo um processo de busca permanente através da experiência educativa.

\section{REFERÊNCIAS}

CARDONA, Patrícia. La poética de la enseñanza: una experiencia. Del Valle: Quinta del Agua Ediciones, 2012.

COURTNEY, Richard. Jogo, teatro \& pensamento. São Paulo: Editora Perspectiva, 2003.

DUDECK, Theresa Robbins. Keith Johnstone: A Critical Biography. London: Bloomsbury Methuen Drama, 2013.

FREIRE, Paulo. Pedagogia do oprimido. 50. ed. rev. e atual. Rio de Janeiro: Paz e Terra, 2011.

GALVÁN, Omar Argentino. Del salto ao vuelo. Manual de impro. Madrid: Ediciones 1MPROTOUR, 2013.

GUSMÃO, Rita; MUNIZ, Mariana Lima. Teatro, formação e mercado de trabalho: um retrato da atuação profissional do egresso da graduação em Teatro da Escola de Belas Artes da UFMG (2002/2009). Lamparina, Belo Horizonte, Universidade Federal de Minas Gerais, Escola de Belas Artes, edição extra (monográfico), v. 1, n. 1, 2012. 
HORTA, Diogo. O Sistema Impro na formação universitária em teatro: experiências nos cursos de graduação em Teatro da EBA/UFMG e da UFSJ. 168 f. Dissertação (Mestrado em Artes). Escola de Belas Artes, Universidade Federal de Minas Gerais, Belo Horizonte, 2014.

JOHNSTONE, Keith. Impro. Improvisation and the theatre. New York: Routledge, 1992.

Impro for Storytellers. New York: Routledge, 1999.

LASSALLE, Jacques; RIVIÈRE, Jean-Loup. Conversas sobre a formação do ator. São Paulo: Perspectiva, 2010.

LUBART, Todd. Psychologie de la créativité. Paris: Armand Colin, 2011.

MADSON, Patricia Ryan. Improv Wisdom: don't prepare, just show up. New York: Bell Tower, 2005.

MUNIZ, Mariana Lima. La improvisación como espectáculo: principales experiências y técnicas de formación del actor-improvisador. Tese (Doutorado em Artes Cênicas) - Faculdad de Filología y Letras, Universidad de Alcalá, Alcalá de Henares, 2005.

SILVESTRE, Rafaela Luiza Silva; VANDENBERGHE, Luc. Os benefícios das emoções positivas. Contextos Clínicos, v. 6, n. 1, p. 50-57, janeiro-junho 2013.

TEIXEIRA, Anísio; WESTBROOK, Robert B. John Dewey. Coleção educadores MEC, Fundação Joaquim Nabuco, Recife-PE: Editora Massangana, 2010. 


\begin{abstract}
This work discusses the professor in undergraduate theatre studies, from a research made at EBA/UFMG and at UFSJ from 2012 to 2014 . The thoughts arising from the observation and the teaching practice in improvisation classes in these universities allow identifying the importance of the professor's performance as an artist in the classroom, strengthening the student's experience in the theatrical research and practice.
\end{abstract}

Keywords: Education. Theatre. Professor-artist.

\title{
Diogo Horta
}

Mestre em Artes pela EBA/UFMG e professor temporário do Curso de Teatro da UFSJ de 2011 a 2013.

diogohort@gmail.com

\section{Mariana de Lima e Muniz}

Doutora em História, Teoria e Prática do Teatro pela Universidad de Alcalá. Professora titular da EBA/UFMG e coordenadora do Programa de Pós-Graduação em Artes da EBA/UFMG.

marianamuniz32@gmail.com 